Check for updates

Cite this: RSC Adv., 2017, 7, 45294

Received 17th July 2017

Accepted 16th September 2017

DOI: $10.1039 / c 7 r a 07867 f$

rsc.li/rsc-advances

\section{Surface and interface engineering of CoNi layered double hydroxides for efficient methanol oxidation reaction $\dagger$}

\begin{abstract}
Shuli Luo, ${ }^{a}$ Lei Qian, (DD *a Menglong Liao, ${ }^{a}$ Xiaorong Hu*a and Dan Xiao (D) ${ }^{\mathrm{b}}$
In this report, surface atomic engineering ( $P$ doping) and interface molecular engineering (coupling with reduced graphene oxide) were adopted to adjusting the chemical compositions, morphological structure, electronic properties and methanol oxidation reaction (MOR) activity of CoNi layered double hydroxides (CoNi LDHs). Low-electronegative $\mathrm{P}$ atom doping can improve the conductivity and induce a synergistic effect to increase MOR activity. Coupling P doped CoNi LDHs (P-CoNi LDHs) with reduced

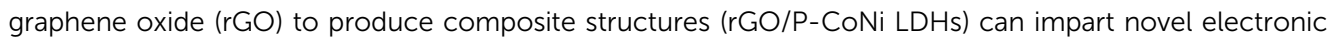
and morphological properties, thereby boosting the MOR activity even further. The P-CoNi LDHs with different morphology and the rGO/P-CoNi LDHs composite were prepared by a cyclic voltammetry (CV) deposition method, which can be directly used as a binder free electrode for MOR. Morphology characterization and electrochemical results indicate that the uniform red-bayberry like P-CoNi LDHs, which were prepared in water solvent, exhibit the highest MOR activity compared with those prepared in alcohol-water component electrolyte, which was 2 times higher than the undoped CoNi LDHs. The introduction of rGO enhance the MOR activity and stability even further, the MOR activity of ball flower like $\mathrm{rGO} / \mathrm{P}$-CoNi LDHs was 1.7 times higher than P-CoNi LDHs, the current density retention is $97 \%$ after $1000 \mathrm{~s}$ at $0.6 \mathrm{~V}$, which is higher than that of P-CoNi LDHs (87\%), but the long-term stability still remains to rise. This report may provide a new insight into design and prepare high electrochemical performance LDHs.
\end{abstract}

\section{Introduction}

In recent years, concerns over the depletion of fossil fuels and increased environmental pollution have triggered significant research efforts in the design and development of novel advanced energy-storage/conversion devices. As one of the most promising clean energy sources, direct methanol fuel cells (DMFCs) have attracted much attention due to the high energy density, easy preparation and environmental friendliness. ${ }^{1}$ According to a number of previous studies, DMFCs mostly work in acid media, but the development of acid DMFCs has been hindered by two key factors. ${ }^{1}$ On the one hand, the electrode kinetics of MOR is slow. On the other hand, only noble-metalbased catalysts can work in acid media. Pt based catalysts have been demonstrated to possess high electrocatalytic activity, ${ }^{2,3}$ but the low utilization, high cost and decaying activity

${ }^{a}$ College of Materials and Chemistry \& Chemical Engineering, Chengdu University of Technology, Chengdu, Sichuan, 610059, China. E-mail: qianlei13@cdut.cn; huxiaorong@cdut.cn

${ }^{b}$ College of Chemistry, Sichuan University, Chengdu, Sichuan, 610064, China $\dagger$ Electronic supplementary information (ESI) available: SEM image of SS/rGO, CV curve of rGO/P-CoNi LDHs in $1 \mathrm{M} \mathrm{KOH}$ and MOR activity of SS/rGO. See DOI: 10.1039/c7ra07867f of these materials limit their commercial application. Consequently, developing cost effective and high-performance electrocatalysts for alkaline-media DMFCs have triggered significant research efforts.

Transition metal oxides/hydroxides are such a class of promising candidates for alkaline MOR because of their low cost and relatively high activity, such as $\mathrm{NiSe}^{4}{ }^{4} \mathrm{Ni}-\mathrm{P}-\mathrm{O}$ compound ${ }^{5}$ and $\mathrm{NiCo}_{2} \mathrm{O}_{4} \cdot{ }^{6,7}$ The transition metals have the empty d orbitals and unpaired electrons. The characteristic chemical adsorption between transition metal and methanol molecule can lower the activation energy markedly. Recently, as a large class of multimetal clay materials, LDHs have been extensively applied in supercapacitors, ${ }^{8}$ catalytic $^{9,10}$ and adsorption/separation processes ${ }^{11,12}$ due to their tunable composition, high-specific capacitance, layered structure, and high dispersion of cations in host layers. But because of the low conductivity and limit active centre, the electrochemical performance of LDHs remains inferior to that of noble metal based electrocatalysts. It has been found that, electronic effect and morphological structure are two important factors that affect the catalyst activity. Electronic effect directly affects the active energy, can accelerate the MOR rate for several orders of magnitude. The morphological structure mainly affects the structure of double layer on the electrode surface, can accelerate 
the MOR rate for one or two orders of magnitude. In this report, surface atomic engineering (heteroatom-doping) and interface molecular engineering (coupling with carbon substrates) were adopt to adjusting the electronic effect and morphological structure of CoNi LDHs, which can induce novel physicochemical properties and strong synergistic effects for MOR, provide new and efficient strategies to greatly enhance the MOR activities.

Heteroatom doping with element of noticeably different electronegativity can tailor their electronic structures and induce a synergistic effect to increase electrochemical activity. Park et al. ${ }^{13}$ reported that the replacement of oxygen with sulphur may create a more flexible structure, because the electronegativity of sulphur is lower than that of oxygen, which prevents the disintegration of the structure by the elongation between layers. The replacement also facilitates electrons transport in the structure. Chen et al. ${ }^{\mathbf{1 4}}$ reported that the replacement of oxygen with sulphur can improve the conductivity, the conductivity of $\mathrm{NiCo}_{2} \mathrm{~S}_{4}$ was at least 100 times higher than that of $\mathrm{NiCo}_{2} \mathrm{O}_{4}$. Tan et al. ${ }^{15}$ reported that the $\mathrm{S}$ doping was useful for the enrichment of surface active sites of the $\mathrm{Co}_{3} \mathrm{O}_{4}$ electrocatalyst. Guo et al. ${ }^{16}$ reported that, $\mathrm{P}$ doped $\mathrm{Co}_{2} \mathrm{Mo}_{3} \mathrm{Se}$ nanosheets provide a positive contribution to improving the hydrogen evolution reaction (HER) activity. Huang et al. ${ }^{17}$ reported that, doping of low-electronegative $\mathrm{P}$ atoms, $\mathrm{MoS}_{2}$ generate an extra oxygen reduction reaction (ORR) activity with four-electron selectivity. The positive contribution of $\mathrm{P}$ doping may due to the following reasons. First, the $\mathrm{P}$ doping can improve the conductivity of semiconductor catalyst then lead to a faster electrochemical kinetics. ${ }^{16}$ Second, the electronegativity of $\mathrm{P}$ is lower than $\mathrm{O}$ and $\mathrm{S}$, on one hand, the low electronegative $\mathrm{P}$ doping is considered to increase the Frontier orbital energy of the semiconductor, which could be beneficial for donating electrons during the ORR processes. ${ }^{18}$ On the other hand, oxygen molecules in the electrolyte may prefer to be absorbed by the low electronegative heteroatoms in plane, which may also accelerate the ORR processes. ${ }^{17}$ Based on the above consideration, in this report, $\mathrm{P}$ doping was used to optimize the electrical conductivity and electronic structure of CoNi LDHs.

Coupling LDHs with carbon substrates to produce composite structures can impart novel physicochemical properties, thereby boosting the electrocatalytic activity even further. ${ }^{19,20}$ Graphene's flexibility, large surface area, and chemical stability, combined with its excellent electrical and thermal conductivity, make it promising as an electrocatalyst. ${ }^{21}$ The graphene can effectively attach metal precursors to grow hydroxide nanoparticles on the surface, the resultant LDHsgraphene hybrid materials present strong interplay from the two components. Such a strong coupling effect may trigger the electronic or chemical modification between the metallic active sites and carbon matrix, produce synergistically enhanced electrochemical performance. ${ }^{22} \mathrm{Ma}$ et al. reported that, the incorporation of $\mathrm{rGO}$ in NiMn LDHs leads to enhanced conductivity and enhanced electrocatalytic activity for oxygen evolution reaction. ${ }^{23}$

Based on the above consideration, in this report, surface atomic engineering ( $\mathrm{P}$ doping) and interface molecular engineering (coupling with rGO) were adopted to adjusting the chemical compositions, morphological structure, electronic properties and MOR activity of CoNi LDHs. The P-CoNi LDHs were prepared by one-step CV deposition method using $\mathrm{NaH}_{2} \mathrm{PO}_{2}$ as $\mathrm{P}$ source. Using water and alcohol-water component solvent as $\mathrm{CV}$ deposition electrolyte, P-CoNi LDHs with different morphologies were prepared and the morphology-activity relationship was discussed. In order to further enhance the MOR activity and stability, the P-CoNi LDHs was coupled with rGO to produce composite structures by a two-steps CV deposition method. The doping of $\mathrm{P}$ element can tailor their electronic structures and induce a synergistic effect to increase MOR activity. The composite structure can impart novel physicochemical and morphological properties, thereby boosting the MOR activity even further.

\section{Experimental procedure}

\subsection{Electrodeposited rGO on stainless steel (SS) substrates}

Before electrodeposition, the SS substrate was cleaned in an ultrasonic bath, first in dilute $\mathrm{HNO}_{3}$, then in acetone, and finally in water. Graphene oxide was prepared by modified Hummer method. ${ }^{24}$ During the electrodeposition process, the SS substrate was used as the working electrode, whereas a Pt and a saturated calomel electrode (SCE) were used as the counter and reference electrodes respectively. The rGO was partly reduced and electrodeposited on SS by $\mathrm{CV}$ method in electrolyte containing $0.1 \mathrm{M} \mathrm{Na}_{2} \mathrm{SO}_{4}$ and $1.0 \mathrm{mg} \mathrm{mL}^{-1}$ graphene oxide. The $\mathrm{CV}$ electrodeposition process was carried out at a scan rate of $50 \mathrm{mV} \mathrm{s}^{-1}$ for 15 cycles within a voltage range of -1.2 to $-0.2 \mathrm{~V} v s$. SCE.

\subsection{Electrodeposited P-CoNi LDHs on blank SS substrate and rGO modified SS substrates}

The P-CoNi LDHs were electrodeposited on blank SS substrate and rGO modified substrate by the previously reported $\mathrm{CV}$ method $^{25}$ in electrolyte containing $0.02 \mathrm{M} \mathrm{Co}\left(\mathrm{NO}_{3}\right)_{2}, 0.01 \mathrm{M}$ $\mathrm{Ni}\left(\mathrm{NO}_{3}\right)_{2}, 0.06 \mathrm{M} \mathrm{NaAc}$ and $0.3 \mathrm{M} \mathrm{NaH}_{2} \mathrm{PO}_{2}$, The CV electrodeposition process was carried out at a scan rate of $5 \mathrm{mV} \mathrm{s}^{-1}$ for 10 cycles within a voltage range of -1.0 to $-0.2 \mathrm{~V} v s$. SCE. The P-CoNi LDHs with different morphology was prepared by using water and alcohol-water component solvent (alcohol : water $=$ $1: 3$, alcohol = ethylene glycol, glycerol and polyethylene glycol-6000 (PEG-6000)) as electrolyte. The morphology evolution of $\mathrm{rGO} / \mathrm{P}-\mathrm{CoNi}$ LDHs was investigated by control the numbers of $\mathrm{CV}$ deposition. The prepared P-CoNi LDHs on blank SS (SS/P-CoNi LDHs) and rGO modified SS (SS/rGO/ P-CoNi LDHs) were cleaned with large amount of water, and subsequently dried in air for $12 \mathrm{~h}$. The mass loading of P-CoNi LDHs on the blank SS and rGO modified SS substrate was approximately $1.0 \mathrm{mg} \mathrm{cm}^{-2}$ on average. Undoped Co-Ni LDHs with similar mass loading were prepared by using the same method just without $\mathrm{NaH}_{2} \mathrm{PO}_{2}$. 


\subsection{Characterization of SS/P-CoNi LDHs and SS/rGO/P-CoNi LDHs}

The prepared $\mathrm{rGO} / \mathrm{P}-\mathrm{CoNi}$ LDHs were characterized by X-ray diffraction spectroscopy (XRD), Raman spectrum, X-ray photoelectron spectroscopy (XPS), inductively coupled plasma-optical emission spectroscopy (ICP-OES), scanning electron microscopy (SEM), transmission electron microscopy (TEM), high resolution transmission electron microscopy (HRTEM) and selected area electron diffraction (SAED). XRD patterns were recorded by using a Tongda DX-2700 X-ray power diffractometer (China) with $\mathrm{Cu} \mathrm{K} \alpha$ radiation. Raman spectrum was recorded by using a Laser Confocal Micro-Raman Spectroscopy (LabRAM HR800, France). XPS patterns were acquired on a Kratos XSAM 800 spectrometer (UK) with a Mg K $\alpha$ X-ray $(1253.6 \mathrm{eV}$ ) excitation source running at $15 \mathrm{kV}$, a hemi-spherical electron energy analyzer and a multichannel detector. The sample for XRD and XPS was peel off from the substrate. ICP-OES were recorded by Perkin Elmer Optima 5300 spectrometer. SEM images were recorded by using a FEI Quanta 250 field-emission scanning electron microscope (American). HRTEM and SAED analyses were conducted on a FEI Tecnai G2 F20 field-emission transmission electron microscope (American).

\subsection{MOR activity measurements of SS/P-CoNi LDHs and SS/rGO/P-CoNi LDHs in alkaline media}

SS/rGO/P-CoNi LDHs and SS/P-CoNi LDHs were directly used as binder free working electrode for evaluating the electrocatalytic activity in alkaline media by CV, chronoamperometry (CA), and electrochemical impedance spectroscopy (EIS) method. Pt and $\mathrm{Hg} / \mathrm{HgO}$ electrode were used as counter and reference electrode. $1 \mathrm{M} \mathrm{KOH}$ with and without $0.5 \mathrm{M}$ methanol were used as the electrolyte. EIS measurements were recorded at the open-circuit potential in the frequency range $100 \mathrm{kHz}$ to $10 \mathrm{MHz}$ with an $\mathrm{AC}$ perturbation of $10 \mathrm{mV}$. All electrochemical measurements were carried out on an Autolab PGSTAT 302N electrochemical workstation at room temperature $\left(25^{\circ} \mathrm{C}\right)$.

\section{Results and discussion}

\subsection{Characterization of SS/P-CoNi LDHs and SS/rGO/P-CoNi LDHs}

In electrodeposition process, the types of electrolyte and the structure of substrate are two important factors which affect the microstructure and electrochemical performance of catalyst. In this report, using water and alcohol-water component solvent as electrolyte, P-CoNi LDHs with different morphologies were obtained. As show in Fig. 1A, in pure water electrolyte, uniform red bayberry like P-CoNi LDHs are observed, the diameters are between $0.6-1.0 \mu \mathrm{m}$. From the inset image in Fig. $1 \mathrm{~A}$ we can find that, the red bayberry like P-CoNi LDHs are composed by small size nanoparticles at about $20 \mathrm{~nm}$. This microstructure may provide large surface area and transport channel for fuel molecule, this is benefit for the adsorption and catalytic oxidation of methanol. In ethylene glycol-water $(1: 3$, Fig. 1B) and glycerol-water (1:3, Fig. 1C) component electrolyte, P-CoNi LDHs with significant different morphology were observed. On

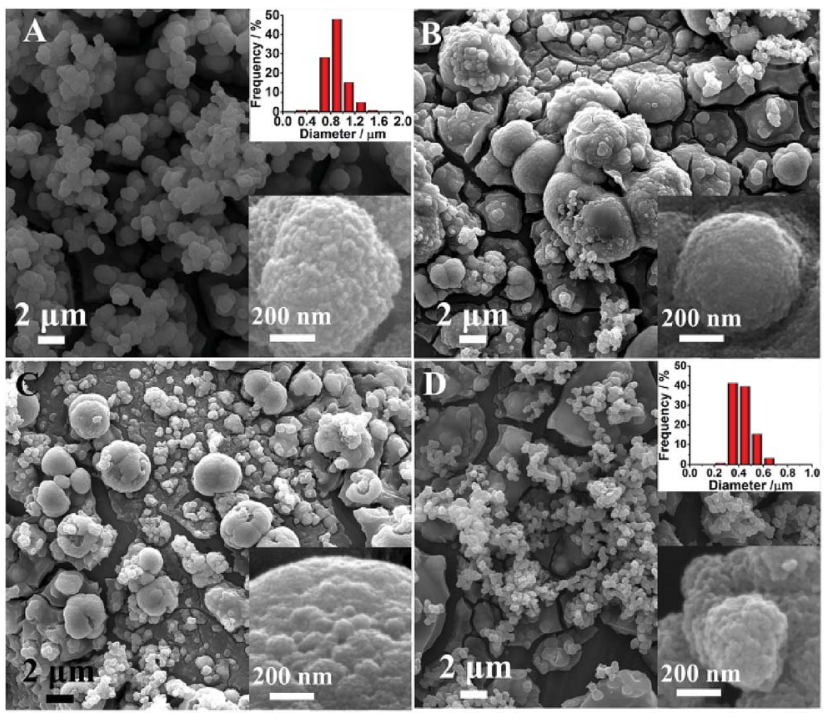

Fig. 1 SEM images of SS/P-CoNi LDHs prepared in water (A), ethylene glycol-water (B), glycerol-water (C) and PEG-6000-water (D) component solvent.

one hand, the size was ununiform, there are some large size cauliflower like P-CoNi LDHs at about $5 \mu \mathrm{m}$. On the other hand, there are some deep cracks on the electrode surface, this may result in the instability of active materials. In PEG-6000-water $(1: 3)$ mix electrolyte, the surface layer of P-CoNi LDHs were similar with that prepared in pure water, but the diameter was smaller, more than $90 \%$ of the nanoparticles are between 0.3 and $0.6 \mu \mathrm{m}$. However, deep cracks also observed at the bottom layer, this may result in structural instability.

As discussed above, using different alcohol-water component solvent as electrolyte, the morphology of P-CoNi LDHs was different in spite of the identical electrodeposition conditions. This phenomenon can be explained as follows. On one hand, the conductivity of pure water and mix solvent electrolyte was different. The conductivity of ethylene glycol, glycol and PEG6000 are lower than the pure water, consequently, the deposition current in alcohol-water component solvent are lower than that in pure water. This may slow down the nucleation process and increase the aggregation of small nanoparticles. From the ethylene glycol to PEG-6000, as the increase of the hydroxyl functional group, the conductivity of mix solvent increased, the morphology of the P-CoNi LDHs in PEG-6000 are similar with that in water. On the other hand, in mix solvent, the chelation between $\mathrm{Co}^{2+} / \mathrm{Ni}^{2+}$ and ethylene glycol, glycol or PEG-6000 also affect the nucleation and the growth process of P-CoNi LDHs.

In the CV deposition process we found that, the P-CoNi LDHs on the blank SS substrate peel off easily. This may due to the weak interaction between the P-CoNi LDHs and blank SS substrate. In order to improve the stability, the blank SS substrate was modified with rGO nanosheets by $\mathrm{CV}$ deposition. The SEM image of the rGO modified SS was shown in Fig. S1. $\dagger$ The lattice works of interwoven metal wires are covered by the rGO nanosheets, which can effectively attach metal precursors to grow hydroxide nanoparticles on the surface, the resultant LDHs-graphene hybrid materials present strong interplay from 
the two components. The strong coupling effect between carbon materials and metal will be favourable to the stability of P-CoNi LDHs.

The $\mathrm{rGO} / \mathrm{P}-\mathrm{CoNi}$ LDHs was firstly characterized by XRD, as shown in Fig. 2A, the position of XRD diffraction peak for $\mathrm{rGO} /$ P-CoNi LDHs was similar with that of $\mathrm{rGO} / \mathrm{CoNi}$ LDHs, the diffraction peaks at $2 \theta$ values of $11.0^{\circ}, 22.4^{\circ}, 34.5^{\circ}, 37.9^{\circ}, 60.5^{\circ}$ can be indexed to a rhombohedral structure of Co-Ni LDHs, which corresponding to the (003), (006), (012), (015) and (110) crystal planes respectively, ${ }^{26}$ no other diffraction peaks were observed. But after P doping, the intensity of diffraction peak decreased. The XRD results indicate that, the prepared P-CoNi LDHs is a typical $\alpha$-phase hydroxides with a hydrotalcite-like structure, the $\mathrm{P}$ doping not change their rhombohedral structure but may reduce their crystallinity. However, XRD results is hard to identify the phase of the rGO due to their relatively low content and ultrathin feature. In order to determine the presence of rGO, Raman spectrum of P-CoNi LDHs (Blue), rGO/PCoNi LDHs (Red) and rGO (Black) were compared as shown in Fig. 2B. The weak peak located at $524 \mathrm{~cm}^{-1}$ in red and blue curves (marked with green circle) may come from the P-CoNi LDHs. ${ }^{27}$ Two bands located at $1352 \mathrm{~cm}^{-1}$ and $1589 \mathrm{~cm}^{-1}$ are observed in rGO and $\mathrm{rGO} / \mathrm{P}-\mathrm{CoNi} \mathrm{LDHs}$, corresponding to the $\mathrm{D}$ and $\mathrm{G}$ band of carbonaceous materials respectively. The $\mathrm{D}$ band is characteristic of the defects and disorder. The $\mathrm{G}$ band represents the vibration of $\mathrm{sp}^{2}$ hybridization carbon, which was restored from electrochemical reduction. ${ }^{28}$ This result demonstrates the presence of rGO. The intensity ratios between $\mathrm{D}$ and G peaks $\left(I_{\mathrm{D}} / I_{\mathrm{G}}\right)$ was measured to be 1.17 for rGO/P-CoNi LDHs, which was slightly higher than that of rGO (1.09), reflecting the increase of unrepaired defects on the rGO surface due to the removal of oxygen containing groups during the P-CoNi LDHs electrodeposition process. ${ }^{29}$

In order to get more information about the $\mathrm{rGO}$ and $\mathrm{P}$ dopant, XPS measurements were performed. As shown in the
XPS survey spectrum (Fig. 2C), the present of element $\mathrm{P}$ indicated that, the $\mathrm{P}$ has doped into the CoNi-LDHs successfully. The oxidation state of $\mathrm{Co}, \mathrm{Ni}, \mathrm{P}, \mathrm{C}$ and $\mathrm{O}$ are analysed by high resolution XPS spectra. By using the Gaussian fitting method, the Co 2p spectrum (Fig. 2D) can be fitted with two shake-up satellites and two spin-orbit doublets, the binding energies at $781.2 \mathrm{eV}$ and $796.8 \mathrm{eV}$ are ascribed to $\mathrm{Co}^{3+}$, another two fitting peaks at 782.5 and $798.3 \mathrm{eV}$ are ascribed to $\mathrm{Co}^{2+}$. In the Ni $2 \mathrm{p}$ spectrum (Fig. 2E), two kinds of nickel species containing $\mathrm{Ni}^{2+}$ and $\mathrm{Ni}^{3+}$ can also be observed, the binding energies at $855.9 \mathrm{eV}$ and $873.7 \mathrm{eV}$ are ascribed to $\mathrm{Ni}^{2+}$. Another two fitting peaks at $857.1 \mathrm{eV}$ and $875.3 \mathrm{eV}$ are ascribed to $\mathrm{Ni}^{3+}$. Compared with previously reported undoped CoNi $\mathrm{LDHs},{ }^{30,31}$ the binding energy of the $\mathrm{Co}^{2+}, \mathrm{Co}^{3+}, \mathrm{Ni}^{2+}$ and $\mathrm{Ni}^{3+}$ are more positive, the positive shift indicates a decrease in the electron density of Co and $\mathrm{Ni}$ in P-CoNi LDHs. This can be ascribed to the surface binding interaction between P-CoNi LDHs and rGO, which induces an electron transfer from P-CoNi LDHs to rGO. ${ }^{32,33}$ This may one of the important factor for the enhanced MOR activity. ${ }^{34}$ For the P 2p high-resolution XPS spectrum (Fig. 2F), the peak observed at $133.3 \mathrm{eV}$ can be ascribed to the $\mathrm{P}-\mathrm{O}$ bonding, the strong $\mathrm{P}-\mathrm{O}$ bonding will increase the catalytic activity. ${ }^{16,35}$ The C 1s spectrum (Fig. 2G) can be fitted with three main peaks at $284.7 \mathrm{eV}, 285.8 \mathrm{eV}$ and $289.2 \mathrm{eV}$, according to the previous reports, ${ }^{19,36}$ these peaks are ascribed to the $\mathrm{C}=\mathrm{C}, \mathrm{C}-\mathrm{C}$ and $\mathrm{O}-\mathrm{C}=\mathrm{O}$ bond in $\mathrm{rGO}$ respectively. The relatively intense and narrow peak of $\mathrm{C}=\mathrm{C}$ demonstrate that most of the carbons in $\mathrm{rGO}$ have been restored to $\mathrm{sp}^{2}$ hybridized carbons, though some remnant carbonyl and other groups are present. The $\mathrm{O} 1 \mathrm{~s}$ spectrum (Fig. $2 \mathrm{H}$ ) can be fitted with two main peaks at $531.5 \mathrm{eV}$ and $532.5 \mathrm{eV}$, the peak at $531.5 \mathrm{eV}$ can be ascribed to the metaloxygen bond in $\mathrm{Ni}(\mathrm{OH})_{2}$ or $\mathrm{Co}(\mathrm{OH})_{2},{ }^{37}$ this result indicates the presence of cobalt and nickel hydroxide. The peak at $532.5 \mathrm{eV}$ can be ascribed to the $\mathrm{C}=\mathrm{O}$ bond in $\mathrm{rGO}^{32,38}$ The above XPS results demonstrate that the surface of our prepared
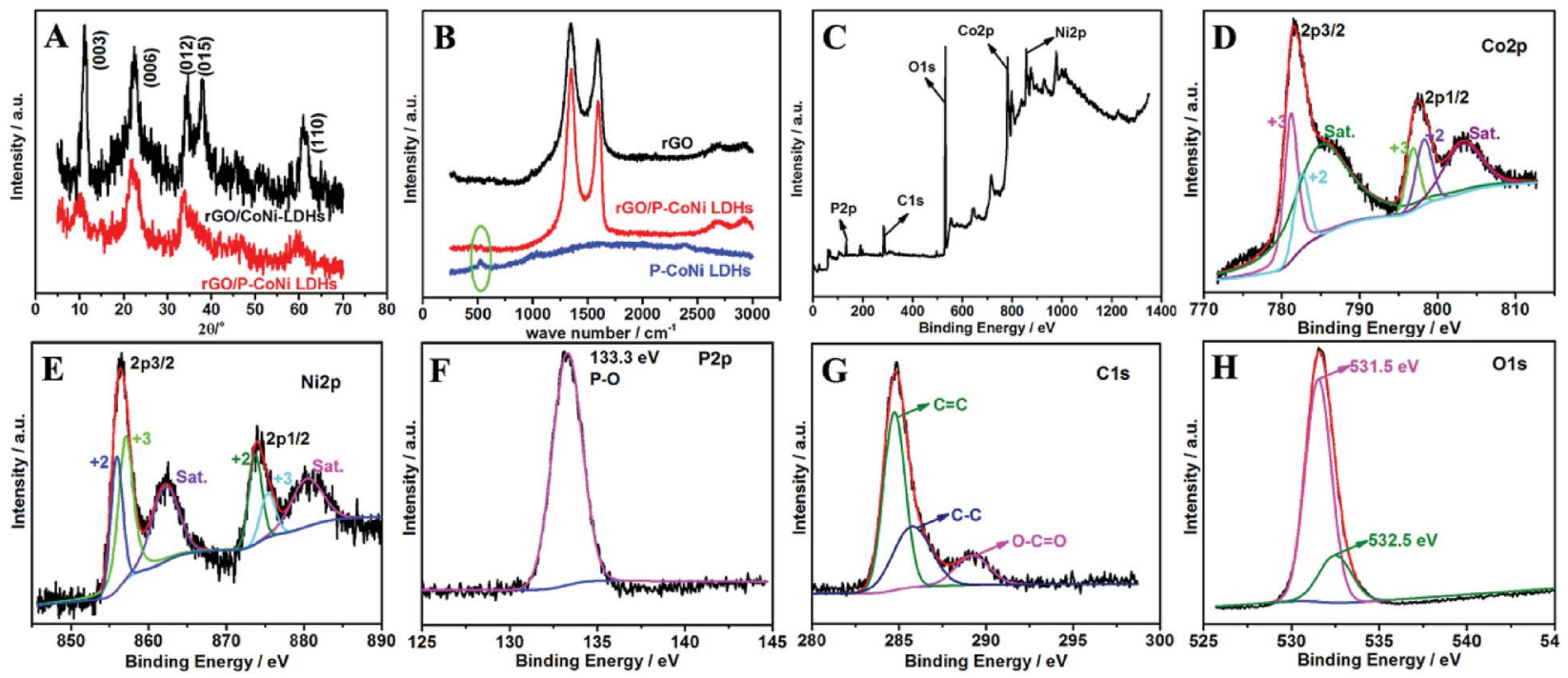

Fig. 2 (A) is the XRD pattern of rGO/CoNi LDHs (black curve) and rGO/P-CoNi LDHs (red curve). (B) is the Raman spectra of rGO (black curve), rGO/P-CoNi LDHs (red curve) and P-CoNi LDHs (blue curve). (C)-(H) are the XPS survey (C), Co 2p (D), Ni 2p (E), P 2p (F), C 1s (G) and O 1s (H) spectra of rGO/P-CoNi LDHs. 
rGO/P-CoNi LDHs has a mixed composition containing $\mathrm{Co}^{2+}$, $\mathrm{Co}^{3+}, \mathrm{Ni}^{2+}, \mathrm{Ni}^{3+}, \mathrm{P}^{\delta+}$ and rGO. The moral ratio of $\mathrm{Ni}, \mathrm{Co}, \mathrm{P}, \mathrm{C}, \mathrm{O}$ was $1: 2.1: 1.0: 2.8: 6.8$. The high $\mathrm{O}$ content may come from the hydroxide, $\mathrm{O}_{2}$ and/or $\mathrm{CO}_{2}$ in air. The ratio of $\mathrm{Ni}$ and Co was roughly equal to $1: 2$, which is consistent with that in precursor solution due to the approximately equal solubility product constant $\left(K_{\mathrm{sp}}\right)$ of $\mathrm{Ni}(\mathrm{OH})_{2}$ and $\mathrm{Co}(\mathrm{OH})_{2} \cdot{ }^{39}$ From the elemental ratio, we can calculate that the atomic ratios of dopant $\mathrm{P}$ to $\mathrm{Co}$ and $\mathrm{Ni}(\mathrm{x}=[\mathrm{P}] /([\mathrm{Co}]+[\mathrm{Ni}]))$ is up to 0.3 , the ICP-OES results shows that the precise $\mathrm{P}$ content (wt\%) in the materials was $16.34 \%$. According to the previous reports, ${ }^{\mathbf{1 6}, 40}$ the high doping level may strongly affect the physical and electrochemical properties of Co-Ni LDHs.

The morphologies of $\mathrm{rGO} / \mathrm{P}-\mathrm{CoNi}$ LDHs were characterized by SEM and TEM. In order to investigate the growth process, the morphology evolution of rGO/P-CoNi LDHs was characterized by controlling the deposition time. After one cycle of CV deposition, some nanoparticles at about $20 \mathrm{~nm}$ anchored on the rGO nanosheets, some nanoparticles self-assemble to form the ringcore structure (Fig. 3A). After two cycles of CV deposition, more nanoparticles assemble on ring-core structure to form the island structure (Fig. 3B). With the CV cycles increased, the size of island structure increased, more and more ball flower like P-CoNi LDHs appeared (Fig. 3C and D). From the inset image in Fig. 3C and D, we can find that, the microstructure of ball flower like rGO/P-CoNi LDHs is different from the red bayberry like P-CoNi LDHs on blank SS (Fig. 1A). The ball flower like rGO/PCoNi LDHs has some distinct morphology characteristics. First, the nanoparticle assembled to from the interconnected network structure, this is benefit for the electron transfer. Second, there are some channels on the surface of the ball flower like rGO/P-CoNi LDHs, which is benefit for the diffusion of fuels and electrolytes. Third, by comparing the SEM images in Fig. 1A and 3D, we can theorize that, the loose ball flower like rGO/P-CoNi LDHs can provide more surface area for methanol adsorption and oxidation. Based on the above consideration,

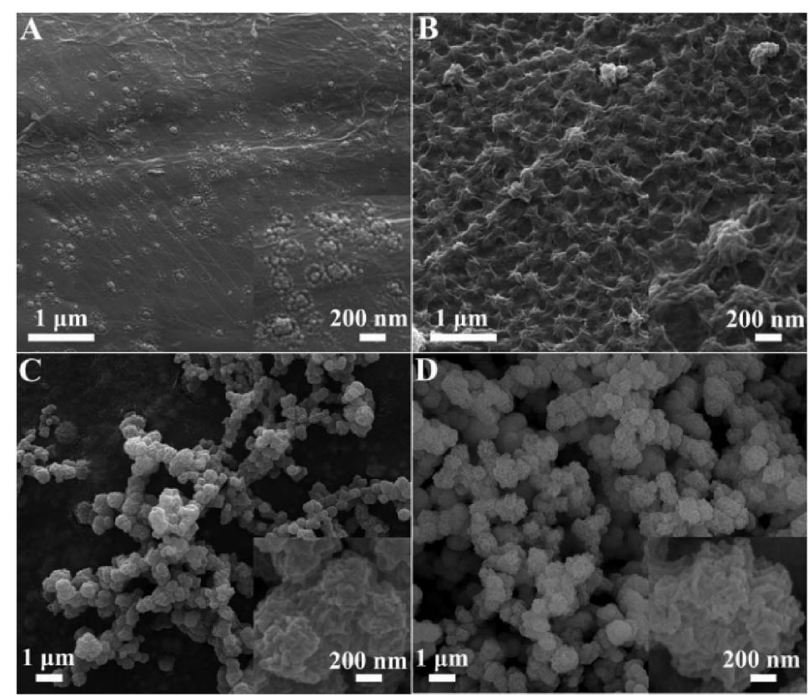

Fig. 3 SEM images of $\mathrm{rGO} / \mathrm{P}-\mathrm{CoNi}$ LDHs deposited by 1 (A), 2 (B), 4 (C) and 7 (D) CV cycles. the distinct morphology characteristics may be another important factor for the enhanced electrochemical activity.

The crystallographic properties of the proposed $\mathrm{rGO} / \mathrm{P}-\mathrm{CoNi}$ LDH was further characterized by TEM, HRTEM and SAED. After one cycle of CV deposition, small size P-CoNi LDHs nanospheres anchored on the surface of rGO nanosheets in a large scale (Fig. 4A1). The diameters of the P-CoNi LDHs nanospheres are between 40 and $100 \mathrm{~nm}$ (Fig. 4A2), this structure is accord with that in Fig. 3A. From the enlarge TEM image in Fig. 4A3 we can find that, the nanosphere may comprised by small nanoparticles, and density of nanoparticles in the core is lower than the shell. The crystallographic properties of rGO nanosheets and P-CoNi LDHs nanosphere are investigated by the HRTEM and SAED. No lattice fringes can be observed in the HRTEM image (Fig. 4A4), only the faint diffraction rings can be observed in SAED image (Fig. 4A5), which may indexed to the $\mathrm{rGO}^{22}$ The HRTEM and SAED results confirming that the rGO nanosheets are amorphous. But for the P-CoNi LDHs nanosphere, the single-crystal nature is confirmed by the clear lattice fringes (Fig. 4A6) and the regular diffraction spots (Fig. 4A7). The interplanar spacing of $0.21 \mathrm{~nm}$ in Fig. $4 \mathrm{A6}$ can be index to the (210) plane of CoP (JCPDS no. 29-0497). As shown in Fig. 4A7, according to the calculation result, the in-plane diffraction spots arranged in a hexagonal pattern corresponding to the (210) plane of CoP (JCPDS no. 29-0497). The HRTEM and SAED results indicate that, after the $\mathrm{P}$ doping, the new phase of CoP was formed, but because of the low content of $\mathrm{P}$ dopant, the CoP phase was not found in the XRD image. As the

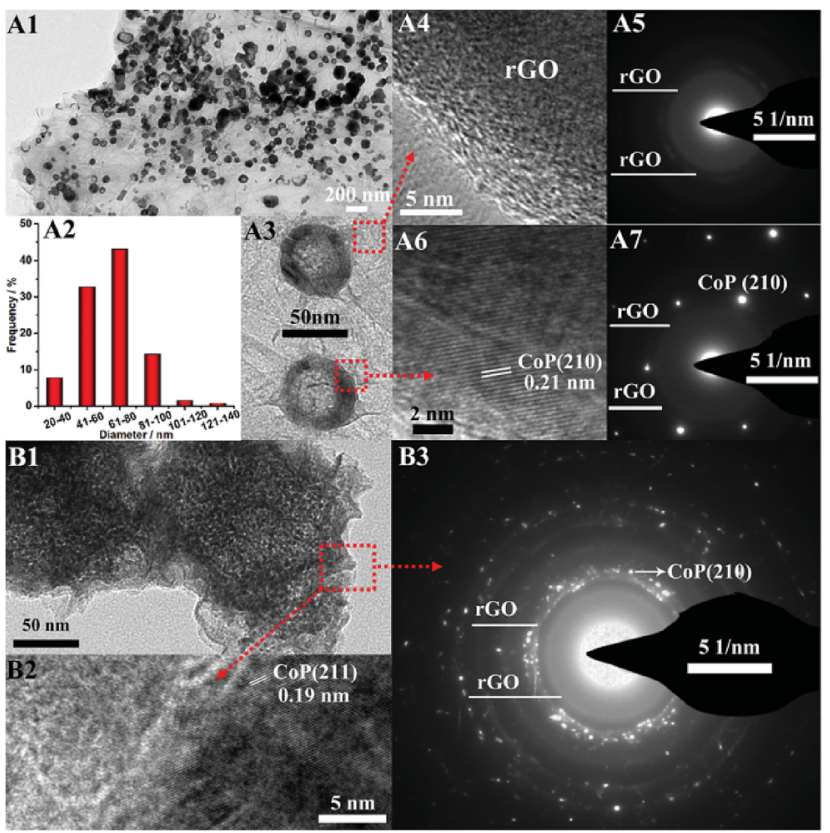

Fig. $4(\mathrm{~A} 1-\mathrm{A} 3)$ are the TEM images (A1 and $\mathrm{A} 2)$ and grain size distribution map (A3) of rGO/P-CoNi LDHs deposited by one CV cycle, (A4) and (A5) are the HRTEM image (A4) and SAED pattern (A5) of rGO nanosheet. (A6) and (A7) are the HRTEM image (A6) and SAED pattern (A7) of P-CoNi LDHs. (B1-B3) are the TEM image (B1), HRTEM image (B2) and SAED pattern (B3) of rGO/P-CoNi LDHs prepared by seven CV cycles. 
cycles of the CV deposition increased, more and more nanoparticles assembled on the shell of the nanospheres. After seven CV cycles, the TEM image of ball flower like rGO/P-CoNi LDHs are shown in Fig. 4B1, which are composed by the small nanoparticles and rGO nanosheets. The interplanar spacing of $0.19 \mathrm{~nm}$ in HRTEM image (Fig. 4B2) can be index to the (211) plane of CoP. ${ }^{25,41}$ The faint diffraction rings index to the rGO and in-plane diffraction spots index to (210) plane of CoP in SAED image (Fig. 4B2) are similar to that in Fig. 4A5 and A7. The TEM, HRTEM and SAED images further revealed that the ball flower like rGO/CoNi-LDHs are constructed with multiple crumpled rGO nanosheets and self-assembled P-CoNi LDHs nanoparticles, the strong coupling between rGO and P-CoNi LDHs is beneficial for increasing the contact area and shortening the transfer distance of electron.

Based on the SEM, TEM, HRTEM and SAED results, we conclude that, the growth process of P-CoNi LDHs consist of three stages (Fig. 5), 2D nucleation, self-assembling and 3D growth. First, the oxygen-containing functional groups on rGO act as anchoring sites for P-CoNi LDHs nucleus, which result in a strong coupling between metal species and rGO, the $2 \mathrm{D}$ rGO nanosheet provide a large surface area for nucleation and growth. Second, the newly formed nanoparticles self-assembled on the surface of the nucleus to form the island-like P-CoNi LDHs. Third, as the CV cycles increased, the size of the island-like P-CoNi LDHs increased, the strong coupling between the rGO nanosheet and P-CoNi LDHs also enhanced, the interaction may make the $2 \mathrm{D}$ rGO nanosheets curled and folded, the bake side of the rGO nanosheet also benefit for the nucleation and $3 \mathrm{D}$ growth. The $3 \mathrm{D}$ growth result in the formation of interconnected ball flower like rGO/P-CoNi LDHs.

\subsection{MOR activity of SS/P-CoNi LDHs and SS/rGO/P-CoNi} LDHs

The contribution of $\mathrm{P}$ doping for the enhanced MOR activity was investigated by EIS, CV and CA measurement. The EIS plot and circuit are shown in Fig. 6A, in this circuit, $R_{\mathrm{s}}, \mathrm{CPE}, R_{\mathrm{ct}}$ and $\mathrm{W}$ are the solution resistance, redox capacitance, charge transfer resistance and Warburg diffusion resistance in the electrode and at the electrode-electrolyte interface. From the EIS plots we can found that, the electron transfer resistance of P-CoNi LDHs was lower than the undoped CoNi LDHs. This result indicates that, the $\mathrm{P}$ doping is an effective method to regulate the electronic structure and improve their intrinsic conductivity. The improved conductivity demonstrate a more facile charge transfer process at

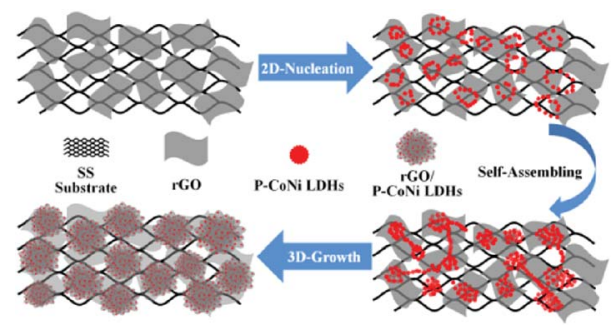

Fig. 5 The proposed growth process of the rGO/P-CoNi LDHs. the electrode/electrolyte interfaces, which is advantageous to realize a better MOR activity. The electrochemical performance of SS/P-CoNi LDHs was evaluated by CV and CA method. As shown in Fig. 6B, in $1 \mathrm{M} \mathrm{KOH}$ electrolyte, distinct pairs of redox peaks are observed at about 0.45 and $0.33 \mathrm{~V}$, these redox peaks are associated with the redox reaction of $\mathrm{M}(\mathrm{OH})_{2} / \mathrm{MOOH}(\mathrm{M}=\mathrm{Co}$, $\mathrm{Ni}) .{ }^{42}$ After the addition of $0.5 \mathrm{M}$ methanol, the current density sharply increased when the potential positive than $0.45 \mathrm{~V}$. This indicate the electrocatalytic oxidation of methanol. The current density increased to $54 \mathrm{~A} \mathrm{~g}^{-1}$ at the potential of $0.6 \mathrm{~V}$, which was almost 5 times higher than that in $1 \mathrm{M} \mathrm{KOH}$ without methanol. The CA results also show that, after $1000 \mathrm{~s}$, the current density at $0.6 \mathrm{~V}$ in $1 \mathrm{M} \mathrm{KOH}$ with $0.5 \mathrm{M}$ methanol was 15 times higher than that in $1 \mathrm{M} \mathrm{KOH}$ without methanol. These results indicate that, the proposed P-CoNi LDHs in pure water has obvious MOR activity. From the CA curves, we also found that, the current density of SS/P-CoNi LDHs at $0.6 \mathrm{~V}$ is 2 times higher than that of undoped CoNi LDHs. This result indicates that, the $\mathrm{P}$ doping tailor their electronic structures and induce a synergistic effect to increase electrochemical activity. The possible reason is that, the electronegativity of $\mathrm{P}$ is lower than that of $\mathrm{O}$, on one hand lowelectronegative $\mathrm{P}$ doping is considered to easily oxidized to form the electrocatalytic active species $\mathrm{MOOH}(\mathrm{M}=\mathrm{Co}, \mathrm{Ni}),{ }^{43}$ on the other hand, methanol molecules in the electrolyte may prefer to be absorbed by the low electronegative heteroatoms in plane, ${ }^{17}$ which may also accelerate the MOR processes.

In order to investigate the relationship between morphology and catalytic activity, the methanol oxidation activity of P-CoNi LDHs with different morphologies were discussed by CV and CA methods. As show in Fig. 7A and B, the MOR activity of ununiform cauliflower like P-CoNi LDHs prepared in ethylene glycol-water and glycerol-water component electrolyte was much lower than that prepared in pure water. The P-CoNi LDHs prepared in water and PEG-6000-water component electrolyte exhibit the similar morphology and catalytic performance. These results indicate that, for the electrocatalyst with the same chemical composition, the catalytic activity is related to the morphology, the following structural characteristics are benefit for the methanol adsorption/oxidation and electron transfer: uniform size, undamaged porous structures and large surface area. Because of the uniform morphology and high MOR activity, the water was used as the solvent for further modifying the chemical composition and MOR activity of P-CoNi LDHs.

The above experiments results indicates that, the P-CoNi LDHs prepared in pure water show the highest MOR activity, but from the black curve in Fig. 7B we can find that, after $1000 \mathrm{~s}$, the current density retention is only $87 \%$. This may due to the loss of the P-CoNi LDHs which present in CV deposition and MOR activity measurement. The possible reason is the weak interaction between SS substrate and P-CoNi LDHs. In order to solve this problem, before the deposition of P-CoNi LDHs, the SS substrate was modified with a thin layer of rGO by CV deposition. Because of the high conductivity and large surface area, the rGO nanosheet not only improve the conductivity of the substrate, but also provide large surface area for the deposition of P-CoNi LDHs and enhance the interaction between the P-CoNi LDHs and rGO through the electrostatic interaction. 

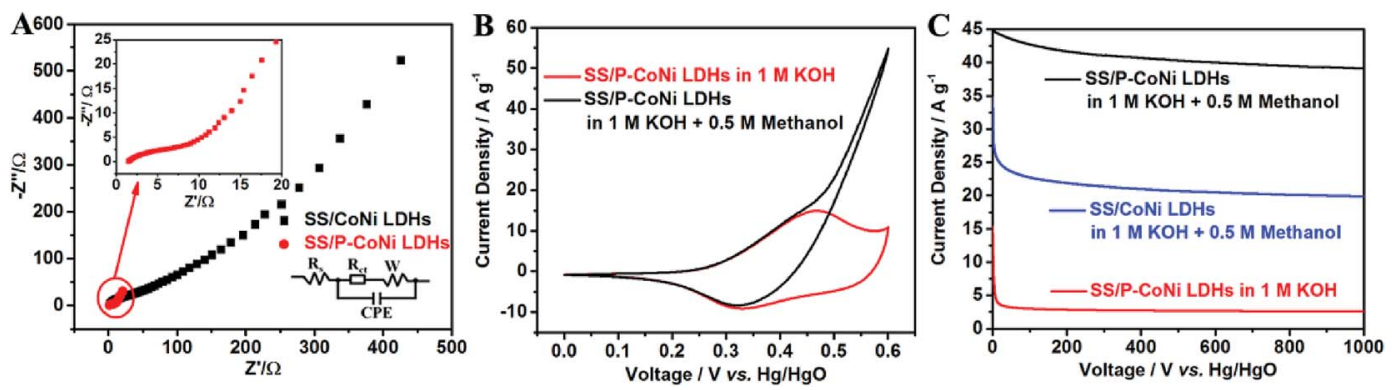

Fig. 6 (A) is the EIS plots of SS/P-CoNi LDHs and SS/CoNi LDHs in $1 \mathrm{M} \mathrm{KOH}$ with $0.5 \mathrm{M}$ methanol. (B) is the CV curves of SS/P-CoNi LDHs in $1 \mathrm{M}$ $\mathrm{KOH}$ electrolyte with (black) and without (red) $0.5 \mathrm{M}$ methanol at scan rate of $10 \mathrm{mV} \mathrm{s}^{-1}$. (C) is the CA curves of SS/P-CoNi LDHs and SS/CoNi $\mathrm{LDH}$ in $1 \mathrm{M} \mathrm{KOH}$ with and without $0.5 \mathrm{M}$ methanol at $0.6 \mathrm{~V}$.
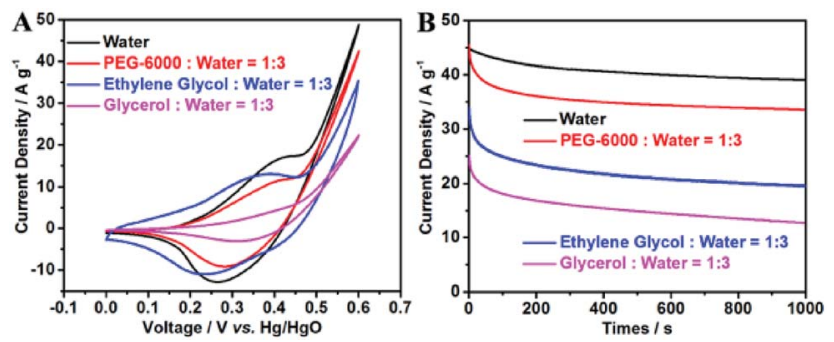

Fig. $7 \mathrm{CV}$ curves (A) at scan rate of $10 \mathrm{mV} \mathrm{s}^{-1}$ and CA curves (B) at $0.6 \mathrm{~V}$ of SS/P-CoNi LDHs in $1 \mathrm{M} \mathrm{KOH}$ electrolyte with $0.5 \mathrm{M}$ methanol. The SS/P-CoNi LDHs were deposited in different alcohol-water component solvent.

The contribution of rGO for the enhanced MOR activity was investigated by EIS, CV and CA measurement. As shown in Fig. 8A, the $R_{\text {ct }}$ of SS/rGO/P-CoNi LDHs was lower than that of SS/P-CoNi LDHs, this may due to the high conductivity of rGO nanosheet, the lower $R_{\mathrm{ct}}$ is benefit for the fast electron transfer in the electrode and at the electrode-electrolyte interface. The degree of current density increase is an important factor for methanol electrocatalytic oxidation. As shown in Fig. 8B, in $1 \mathrm{M}$ $\mathrm{KOH}$ electrolyte with $0.5 \mathrm{M}$ methanol, the current density at $0.6 \mathrm{~V}$ for $\mathrm{SS} / \mathrm{rGO} / \mathrm{P}-\mathrm{CoNi} \mathrm{LDHs}$ electrode is up to $77 \mathrm{~A} \mathrm{~g}^{-1}$, which is 6.4 times higher than that in $1 \mathrm{M} \mathrm{KOH}$ without methanol (Fig. S2 $\dagger$ ). This result is superior to the $\mathrm{S}$ doped Co-Ni LDHs (5.5 times at $0.6 \mathrm{~V} v s . \mathrm{Hg} / \mathrm{HgO}),{ }^{44} \mathrm{Ni} / \mathrm{Al} \mathrm{LDHs}$ film $(2.4$ times at $0.8 \mathrm{~V}$ vs. $\mathrm{SCE})^{45}$ and $\mathrm{Ni} / \mathrm{Al}$ LDHs support (4.2 times at $0.8 \mathrm{~V}$ vs. SCE). ${ }^{46}$
As shown in Fig. 8C, the current density of SS/rGO/P-CoNi LDHs at $0.6 \mathrm{~V}$ after $1000 \mathrm{~s}$ is 1.7 times higher than that of $\mathrm{SS} / \mathrm{P}-\mathrm{CoNi}$ LDHs. The stability of the SS/rGO/P-CoNi LDHs electrode is also improved, after $1000 \mathrm{~s}$, the current density retention of $\mathrm{SS} / \mathrm{rGO} / \mathrm{P}-\mathrm{CoNi} \mathrm{LDHs}$ is $97 \%$, which is higher than that of SS/P-CoNi LDHs (87\%). The CV and CA results indicate that, though the rGO alone exhibits poor MOR activity (Fig. S3†), it can largely contribute to the improvement of MOR activity of rGO/P-CoNi LDHs composites. The possible reason was as follows. On one hand, rGO can improve the conductivity of SS/rGO/P-CoNi LDHs electrodes, which could accelerate the charge transfer. ${ }^{47}$ On the other hand, rGO can act as an effective matrix for anchoring the P-CoNi LDHs, which improve the stability, prevent the aggregation of the P-CoNi LDHs and make them effectively accessible by electrolyte ions, the strong coupling effect between rGO and P-CoNi LDHs impart novel physicochemical and morphological properties, thereby boosting the MOR activity. ${ }^{19,20}$ Therefore, rGO in rGO/P-CoNi LDHs composites serve dual functions as both conductive channels and active interface centres.

Using the identical method, the SS/rGO/P-Co(OH $)_{2}$ and SS/ $\mathrm{rGO} / \mathrm{P}-\mathrm{Ni}(\mathrm{OH})_{2}$ were prepared and their MOR activity were also investigated by EIS, CV and CA methods. As shown in Fig. 9A, the $R_{\text {ct }}$ of $\mathrm{SS} / \mathrm{rGO} / \mathrm{P}-\mathrm{CoNi} \mathrm{LDHs}$ is lower than that of $\mathrm{SS} / \mathrm{rGO} / \mathrm{P}-$ $\mathrm{Ni}(\mathrm{OH})_{2}$ and $\mathrm{SS} / \mathrm{rGO} / \mathrm{P}-\mathrm{Co}(\mathrm{OH})_{2}$. This result indicates the high conductivity of SS/rGO/P-CoNi LDHs, which can accelerate the electron transfer during the MOR process. As shown in Fig. 9B, the current density of SS/rGO/P-CoNi LDHs is almost 4 times
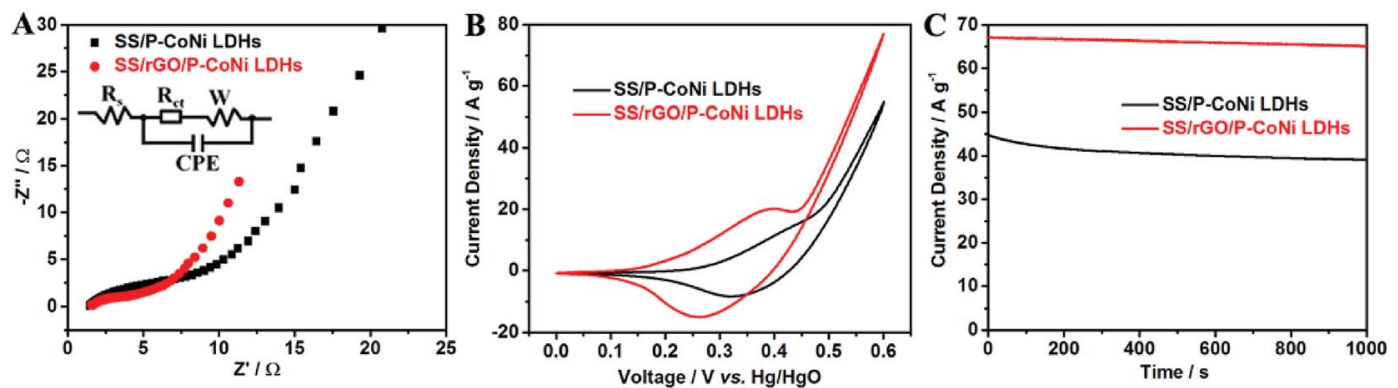

Fig. 8 The EIS plots (A), CV curves (B) and CA curves (C) of SS/rGO/P-CoNi LDHs (red) and SS/P-CoNi LDHs (black) in 1 M KOH electrolyte with $0.5 \mathrm{M}$ methanol. 

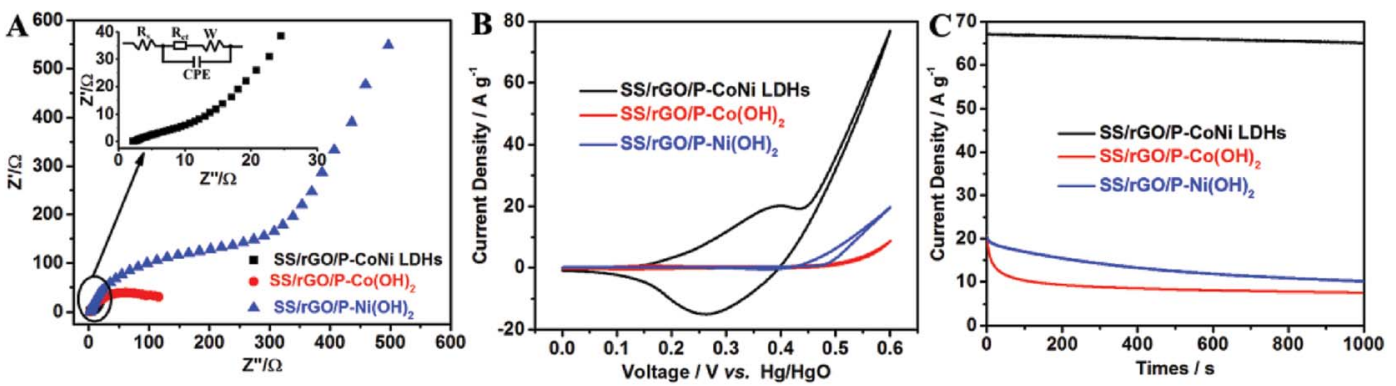

Fig. 9 The EIS plots (A), CV curves at scan rate of $10 \mathrm{mV} \mathrm{s}^{-1}$ (B) and CA curves at $0.6 \mathrm{~V}(\mathrm{C})$ of SS/rGO/P-CoNi LDHs (black), SS/rGO/P-Co(OH) 2 (red) and $\mathrm{SS} / \mathrm{rGO} / \mathrm{P}-\mathrm{Ni}(\mathrm{OH})_{2}$ (blue).
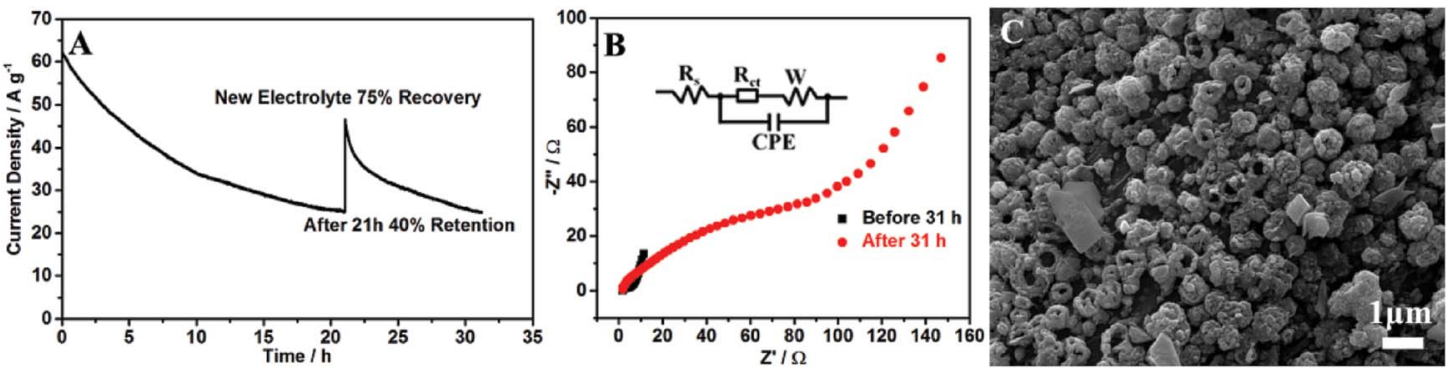

Fig. 10 (A) is the long-term CA curves of the SS/rGO/P-CoNi LDHs, (B) is the EIS plots of SS/rGO/P-CoNi LDHs before and after long-term CA measurement, $(\mathrm{C})$ is the SEM image of SS/rGO/P-CONi LDHs after long-term CA measurements.

higher than that of $\mathrm{SS} / \mathrm{rGO} / \mathrm{P}-\mathrm{Ni}(\mathrm{OH})_{2}$ and 8 times higher than the $\mathrm{SS} / \mathrm{rGO} / \mathrm{P}-\mathrm{Co}(\mathrm{OH})_{2}$. These results are accord with the CA results. From the CA results we can also found that, the stability of the $\mathrm{SS} / \mathrm{rGO} / \mathrm{P}-\mathrm{CoNi}$ LDHs is higher than that of $\mathrm{SS} / \mathrm{rGO} / \mathrm{P}-$ $\mathrm{Co}(\mathrm{OH})_{2}$ and $\mathrm{SS} / \mathrm{rGO} / \mathrm{P}-\mathrm{Ni}(\mathrm{OH})_{2}$. The $\mathrm{CV}$ and CA results indicate that the incorporation of cobalt and nickel in the host layer can offer an effective way for achieving an improved electrochemical performance in comparison with monometallic hydroxide, the possible reasons are as follows. First, the synergistic contributions from both nickel and cobalt ions are expected to richer redox reactions than the two corresponding single component hydroxide. ${ }^{48}$ Second, the conductivity of SS/rGO/P-CoNi LDHs was higher than $\mathrm{SS} / \mathrm{rGO} / \mathrm{P}-\mathrm{Co}(\mathrm{OH})_{2}$ and $\mathrm{SS} / \mathrm{rGO} / \mathrm{P}-\mathrm{Ni}(\mathrm{OH})_{2}$, the high conductivity is beneficial for the fast electron transfer in the electrode and at the electrode-electrolyte interface..$^{20}$ Third, cobalt allows the nickel to reach a higher oxidation state and promotes the electron transfer during the MOR process. ${ }^{49,50}$

The long-term stability of the SS/rGO/P-CoNi LDHs was investigated by CA methods. As shown in Fig. 10A, the current density decay was observed, but the speed was slow down gradually, after 21 hours, only $40 \%$ retained. By replacing the electrolyte, the current density returned to $75 \%$ of the original value. In order to investigating the reason of current decay, the morphology characterization and charge transfer resistance measurement after $31 \mathrm{~h}$ were carried out. As shown in Fig. 10B, after $31 \mathrm{~h}$, the charge transfer resistance increase, this may due to the adsorption of oxidation intermediate and the damage of the structure during the CA measurement. As shown in Fig. 10C, the morphology of the rGO/P-CoNi LDHs was different from that in Fig. 3D, after $31 \mathrm{~h}$, the ball flower was replaced by hollow nanobowl, the collapsed structure may due to the large current density during the CA measurement. The CA, EIS and SEM results indicate that, the consumption of methanol, the adsorption of oxidation intermediate and the collapsed structure are responsible for the current density decay. Despite the inferior electrochemical stability, the attractive MOR activity of our proposed $\mathrm{rGO} / \mathrm{P}-\mathrm{CoNi}$ LDHs inspires us to improve it in latter studies.

\section{Conclusions}

In summary, through $\mathrm{P}$ doping and introduction of rGO nanosheets, the MOR activity and stability of CoNi LDHs was enhanced. The low-electronegative $\mathrm{P}$ atoms doping can tailor their electronic structures and improve the conductivity. The MOR activity of P-CoNi LDHs was 2 times higher than the undoped CoNi LDHs. By using water and water-alcohol component solvent as electrolyte, the uniform red bayberry like and ununiform cauliflower like P-CoNi LDHs were prepared and the activity-morphology relationship was discussed. Electrochemical results indicate that, the uniform red bayberry like P-CoNi LDHs exhibit the higher MOR activity than the ununiform cauliflower like P-CoNi LDHs. Coupling PCoNi LDHs with rGO to produce composite structures can impart novel physicochemical and morphological properties, thereby boosting the MOR activity even further. The MOR activity of rGO/P-CoNi LDHs not only higher than the P-CoNi LDHs but also higher than the $\mathrm{rGO} / \mathrm{P}-\mathrm{Co}(\mathrm{OH})_{2}$ and $\mathrm{rGO} / \mathrm{P}-$ $\mathrm{Ni}(\mathrm{OH})_{2}$. For this promising methanol oxidation non platinum electrocatalyst, the inferior long-term stability is the main 
obstacle for the commercialization, this is the clear next step for our proposed rGO/P-CoNi LDHs electrocatalyst.

\section{Conflicts of interest}

There are no conflicts to declare.

\section{Acknowledgements}

The authors gratefully acknowledge the research start financial support, the cultivating program of middle-aged backbone teachers from Chengdu University of Technology and the fund form the Education Department of Sichuan Province (SZR025). We also express our thanks to Mr Mingshi Feng of the State Key Laboratory of Oil and Gas Reservoir Geology and Exploitation (Chengdu University of Technology) for taking the SEM images.

\section{Notes and references}

1 N. Kimiaie, K. Wedlich, M. Hehemann, R. Lambertz, M. Muller, C. Korte and D. Stolten, Energy Environ. Sci., 2014, 7, 3013-3025.

2 Y. Qin, L. Chao, J. Yuan, Y. Liu, F. Chu, Y. Kong, Y. Tao and M. Liu, Chem. Commun., 2015, 52, 382-385.

3 X. Sun, X. Zhu, N. Zhang, J. Guo, S. Guo and X. Huang, Chem. Commun., 2015, 51, 3529-3532.

4 Q. Luo, M. Peng, X. Sun and A. M. Asiri, $R S C A d v$., 2015, 5, 87051-87054.

5 Y. Y. Tong, C. D. Gu, J. L. Zhang, M. L. Huang, H. Tang, X. L. Wang and J. P. Tu, J. Mater. Chem. A, 2015, 3, 4669-4678.

6 R. Ding, L. Qi, M. J. Jia and H. Y. Wang, J. Power Sources, 2014, 251, 287-295.

7 L. Qian, L. Gu, L. Yang, H. Y. Yuan and D. Xiao, Nanoscale, 2013, 5, 7388-7396.

8 X. J. Gao, H. P. Lv, Z. H. Li, Q. J. Xu, H. M. Liu, Y. G. Wang and Y. Y. Xia, RSC Adv., 2016, 6, 107278-107285.

9 G. Fan, F. Li, D. G. Evans and X. Duan, Chem. Soc. Rev., 2014, 43, 7040-7066.

10 S. Chitravathi, S. Kumar and N. Munichandraiah, RSC Adv., 2016, 6, 103106-103115.

11 N. Tarutani, Y. Tokudome, M. Fukui, K. Nakanishi and M. Takahashi, RSC Adv., 2015, 5, 57187-57192.

12 J. Qu, X. M. He, X. W. Li, Z. Q. Ai, Y. J. Li, Q. W. Zhang and X. Z. Liu, RSC Adv., 2017, 7, 31466-31474.

13 S. H. Park, Y.-K. Sun, K. S. Park, K. S. Nahm, Y. S. Lee and M. Yoshio, Electrochim. Acta, 2002, 47, 1721-1726.

14 H. C. Chen, J. J. Jiang, L. Zhang, H. Z. Wan, T. Qi and D. D. Xia, Nanoscale, 2013, 5, 8879-8883.

15 Z. J. Tan, P. R. Liu, H. M. Zhang, Y. Wang, M. Al-Mamun, H. G. Yang, D. Wang, Z. Y. Tang and H. J. Zhao, Chem. Commun., 2015, 51, 5695-5697.

16 Y. X. Guo, Z. Y. Yao, C. S. Shang and E. K. Wang, J. Mater. Chem. A, 2017, 5, 12043-12047.

17 H. Huang, X. Feng, C. Du and W. Song, Chem. Commun., 2015, 51, 7903-7906.

18 Q. Yue, S. Chang, S. Qin and J. Li, Phys. Lett. A, 2013, 377, 1362-1367.
19 J. Chen, X. Wang, J. Wang and P. S. Lee, Adv. Energy Mater., 2016, 6, 1501745.

20 Y. P. Zhu, C. Guo, Y. Zheng and S.-Z. Qiao, Acc. Chem. Res., 2017, 50, 915-923.

21 F. Bonaccorso, L. Colombo, G. Yu, M. Stoller, V. Tozzini, A. C. Ferrari, R. S. Ruoff and V. Pellegrini, Science, 2015, 347, 1246501.

22 X. Ge, C. Gu, Z. Yin, X. Wang, J. Tu and J. Li, Nano Energy, 2016, 20, 185-193.

23 W. Ma, R. Ma, J. Wu, P. Sun, X. Liu, K. Zhou and T. Sasaki, Nanoscale, 2016, 8, 10425-10432.

24 D. Pan, S. Wang, B. Zhao, M. Wu, H. Zhang, Y. Wang and Z. Jiao, Chem. Mater., 2009, 21, 3136-3142.

25 J. Yu, Q. Li, Y. Li, C.-Y. Xu, L. Zhen, V. P. Dravid and J. Wu, Adv. Funct. Mater., 2016, 26, 7644-7651.

26 C. Vaysse, L. Guerlou-Demourgues, A. Demourgues, F. Lazartigues, D. Fertier and C. Delmas, J. Mater. Chem., 2002, 12, 1035-1043.

27 P. Huang, C. Cao, Y. Sun, S. Yang, F. Wei and W. Song, J. Mater. Chem. A, 2015, 3, 10858-10863.

28 C. Y. Foo, A. Sumboja, D. J. H. Tan, J. Wang and P. S. Lee, Adv. Energy Mater., 2014, 4, 1400236.

29 P. Si, S. Ding, X.-W. Lou and D.-H. Kim, RSC Adv., 2011, 1, 1271-1278.

30 D. Zha, H. Sun, Y. Fu, X. Ouyang and X. Wang, Electrochim. Acta, 2017, 236, 18-27.

31 C. Wang, X. Zhang, Z. Xu, X. Sun and Y. Ma, ACS Appl. Mater. Interfaces, 2015, 7, 19601-19610.

32 F. Ning, M. Shao, S. Xu, Y. Fu, R. Zhang, M. Wei, D. G. Evans and X. Duan, Energy Environ. Sci., 2016, 9, 2633-2643.

33 M. S. A. Sher Shah, A. R. Park, K. Zhang, J. H. Park and P. J. Yoo, ACS Appl. Mater. Interfaces, 2012, 4, 38933901.

34 E. J. Popczun, J. R. McKone, C. G. Read, A. J. Biacchi, A. M. Wiltrout, N. S. Lewis and R. E. Schaak, J. Am. Chem. Soc., 2013, 135, 9267-9270.

35 Y.-J. Tang, M.-R. Gao, C.-H. Liu, S.-L. Li, H.-L. Jiang, Y.-Q. Lan, M. Han and S.-H. Yu, Angew. Chem., Int. Ed., 2015, 54, 12928-12932.

36 W. S. V. Lee, M. Leng, M. Li, X. L. Huang and J. M. Xue, Nano Energy, 2015, 12, 250-257.

37 N. S. McIntyre and M. G. Cook, Anal. Chem., 1975, 47, 22082213.

38 Y. Wang, Y. Shao, D. W. Matson, J. Li and Y. Lin, ACS Nano, 2010, 4, 1790-1798.

39 X. Li, W. Sun, L. Wang, Y. Qi, T. Guo, X. Zhao and X. Yan, RSC Adv., 2015, 5, 7976-7985.

40 M. H. Z. Maha, M. M. Bagheri-Mohagheghi, H. Azimi-Juybari and M. Shokooh-Saremi, Phys. Scr., 2012, 86, 055701.

41 Y. P. Zhu, Y. P. Liu, T. Z. Ren and Z. Y. Yuan, Adv. Funct. Mater., 2015, 25, 7337-7347.

42 H. L. Wang, Q. M. Gao and L. Jiang, Small, 2011, 7, 24542459.

43 D. Chen and S. D. Minteer, J. Power Sources, 2015, 284, 27-37. 44 L. Qian, W. Chen, M. Liu, Q. Jia and D. Xiao, ChemElectroChem, 2016, 3, 950-958. 
45 Y. Wang, D. Zhang, W. Peng, L. Liu and M. Li, Electrochim. Acta, 2011, 56, 5754-5758.

46 Y. Wang, H. Ji, W. Peng, L. Liu, F. Gao and M. Li, Int. J. Hydrogen Energy, 2012, 37, 9324-9329.

47 Y. Wimalasiri, R. Fan, X. S. Zhao and L. Zou, Electrochim. 50 J.-W. Kim and S.-M. Park, J. Electrochem. Soc., 2003, 150, Acta, 2014, 134, 127-135.
48 J. W. Xiao, L. Wan, S. H. Yang, F. Xiao and S. Wang, Nano Lett., 2014, 14, 831-838.

49 R. D. Armstrong and E. A. Charles, J. Power Sources, 1989, 25, 89-97. 